\title{
LA PANDEMIA POR CORONAVIRUS A TRAVÉS DE VIÑETAS DE HUMOR GRÁFICO
}

\section{Coronavirus Pandemic through Cartoon Graphics}

\author{
Agustín HIDALGO ${ }^{\mathrm{a}, \mathrm{b}, \mathrm{c}}$; Begoña CANTABRANA ${ }^{\mathrm{a}, \mathrm{b}, \mathrm{c}}$; Covadonga DIEGO ${ }^{\mathrm{j}}$; Iñigo HIDALGO \\ aÁrea de Farmacología, Departamento de Medicina, Universidad de Oviedo. 'Instituto Universitario de

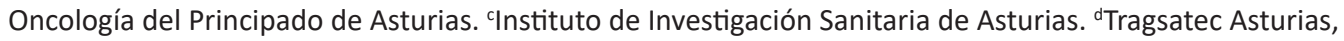 \\ eBabcock Mission Critical Service (España). \\ Correo electrónico: hidalgo@uniovi.es
}

Fecha de recepción: 29 de septiembre de 2020

Fecha de aceptación: 30 de septiembre de 2020

Fecha de publicación: 29 de enero de 2021

\begin{abstract}
Resumen
El humor, que tiene la función de aliviar la tensión emocional, el miedo y la inseguridad, aporta una lectura crítica de la realidad que se ha reflejado en las viñetas editadas en el diario El País durante la pandemia, cuyos primeros 6 meses se comentan a través del trabajo de los humoristas El Roto, Peridis, Flavita Banana y Malagón. Las historias contadas pueden agruparse en categorías como el estado general del mundo, el origen y difusión de la pandemia, la comunicación y su manipulación, el confinamiento, el miedo, los recursos sanitarios y los sistemas de salud, la crisis política y la economía. El trabajo de los humoristas sugiere que las crisis siempre benefician y perjudican a los mismos, que la política tiene sus dinámicas propias alejadas de la ciudadanía y sus problemas, que las condiciones ambientales, cada vez más deterioradas, y las formas de vida favorecen las pandemias y que las formas de respuesta al problema son las mismas de siempre, acentuadas por el desmantelamiento de la sanidad pública y la desinformación.
\end{abstract}

Palabras clave: humor gráfico; pandemia; COVID-19; prensa; repercusiones sociales; diario El País. 


\title{
LA PANDEMIA POR CORONAVIRUS A TRAVÉS DE VIÑETAS DE HUMOR GRÁFICO AGUSTÍN HIDALGO; BEGOÑA CANTABRANA; COVADONGA DIEGO; IÑIGO HIDALGO
}

\begin{abstract}
Humor; which has the function of relieving emotional tension; fear and insecurity; provides a critical reading of reality that has been reflected in the cartoons published in the newspaper El País during the pandemic; whose first 6 months are commented on through the work of the cartoonists El Roto, Peridis, Flavita Banana and Malagón. The stories told can be grouped into categories such as the general state of the world; the origin and spread of the pandemic; the communication and its manipulation; containment; fear; health resources and health systems; political crisis and the economy. The work of the cartoonists suggests that crises always benefit and harm them; as well as politics has its own dynamics far from the citizenry and its problems; and that environmental conditions; increasingly deteriorated; and lifestyles favor pandemics. Moreover; the forms of response to the problem are the same as always; accentuated by the dismantling of public health and misinformation.
\end{abstract}

Keywords: cartoon graphic; pandemic; COVID-19; press; social impact; newspaper El País.

"Los relatos no son inocentes, no del todo inocentes"

(Luis Landero ${ }^{1}$ )

\section{INTRODUCCIÓN}

El término humor es polisémico y, como concepto, abarca varias dimensiones ${ }^{2}$ : a) cognitiva, como forma de mirar el mundo e interpretar lo que sucede; b) afectiva, la forma de sentirnos con buen ánimo ante los acontecimientos de la vida; c) comportamental, o sea la forma de manifestar nuestro sentido del humor; y d) social, con un importante papel en la relación interpersonal.

El humor, como actividad artística y cultural, admite múltiples presentaciones, cada una de las cuales tiene unas características específicas acordes con el medio y el formato ${ }^{3}$. Así, el humor puede ser verbal (chistes, juegos de palabras, anécdotas, etc.), auditivo (imitaciones, ruidos), visual (payasos, mimo, guiñol, etc.) o figurativo (comics, viñetas, humor gráfico, etc.). También se pueden establecer distingos según el sector al que se dirige la actividad (deportivo, político, etc.), según los soportes (cine, papel, etc.) y, dentro de las categorías del humor en documentos impresos, tal vez el que tiene mayor predicamento es el humor gráfico con viñetas ilustradas que cuentan una historia. Este humor gráfico está presente en los diarios de información general, bien sea a través de una viñeta única o de una limitada colección de ellas.

El humor y la prensa escrita forman una unidad casi indivisible como sugiere su íntima asociación desde hace muchos años, la asunción de un humor característico por medios concretos y/o el hecho de que muchos lectores no entenderíamos una información sin humor, sin olvidar a los que comienzan la lectura de su diario de cabecera por la viñeta de su humorista favorito.

Por otra parte, el humor y la medicina han estado unidos desde siempre dada la variedad de situaciones que ofrece la actividad médica que puede prestarse a interpretaciones cómicas, al recurso al sarcasmo, o sencillamente a la crítica mordaz. Además, algunos de los grandes humoristas de España han recurrido o recurren habitualmente a cuestiones relacionadas con la salud, tanto en cuanto a la prevención como a las propias situaciones de algunas enfermedades o al alcance de las mismas ${ }^{4}$. El gran humorista Antonio Fraguas (Forges) incluyó con frecuencia los temas sanitarios dentro de su universo humorístico y de crítica social, del que nos ha dejado ejemplos emblemáticos ${ }^{5,6}$. Otros, como Chumy Chumez ${ }^{7}$, James Gorman ${ }^{8}$ o Juan Jacinto Muñoz Rengel ${ }^{9}$, han hecho virtud de su humor para enfrentar la hipocondría. 


\section{LA PANDEMIA POR CORONAVIRUS A TRAVÉS DE VIÑETAS DE HUMOR GRÁFICO AGUSTÍN HIDALGO; BEGOÑA CANTABRANA; COVADONGA DIEGO; IÑIGO HIDALGO}

Por último, el humor gráfico ha sido utilizado por su valor formativo en estudiantes de medicina ${ }^{10}$ así como para ponderar los comportamientos éticos de los profesionales sanitarios ${ }^{11}$ y para educación de la ciudadanía en temas de salud $^{12,13}$.

En resumidas cuentas, el humor nos permite una interpretación liberadora de los acontecimientos cotidianos o, al menos, aliviar la tensión generada por situaciones incidentales, disponer el ánimo para la acción y/o fustigar a los "responsables" de las situaciones que son objetivo del humorista. Con este enfoque, en el presente artículo hemos realizado una lectura de las viñetas de humor relacionadas con la pandemia de la COVID-19 publicadas en un diario generalista de ámbito nacional en su edición impresa.

\section{MATERIAL y MÉTODOS}

El material utilizado para la elaboración de este artículo está integrado por las viñetas de humor del diario El País publicadas entre el día 2 de enero y el 30 de junio de 2020 en su edición impresa. No obstante, por su significación en el contexto de este trabajo se ha incluido alguna viñeta de fechas posteriores. Para identificarlas, se ha consultado la edición en papel y se ha realizado una búsqueda en Internet a través de Google utilizando los términos de búsqueda: a) viñetas de humor de El País y b) artículos escritos por Andrés Rábago para El País.

En el diario El País, publican viñetas humoristas como Andrés Rábago (El Roto), José María Pérez (Peridis), Flavia Álvarez-Pedrosa Pruvost (Flavita Banana), José Rubio Malagón, Sciammarella, Liniers y Max. Sin embargo, los que mantienen una presencia diaria son El Roto, autor de la viñeta editorial y Peridis, con presencia cada vez más frecuente de Flavita Banana.
El resto tiene una presencia más esporádica y su trabajo se suele inscribir en los suplementos Babelia, El Viajero, Ideas, Negocios, en El País Semanal o en la edición electrónica del diario. A efectos de este artículo nos hemos centrado fundamentalmente en las viñetas de El Roto y, para aspectos más puntuales, en las historias que cuentan los otros humoristas.'

Hemos elegido El Roto por el carácter más social de su trabajo. Su estilo puede ser calificado como satírico, filosófico y conceptual, otorgando un contexto social y ético a su actividad que consiste en dejar constancia de la actualidad y circunscribirla a una actividad humana siempre mejorable. El trabajo del humorista José María Pérez (Peridis) está orientado más a resaltar el debate o enfrentamiento político del momento del que ha resaltado algunas peculiaridades como la instrumentalización de la oposición y las autonomías para obtener beneficios. El resto ha tenido una incidencia menor en la pandemia aunque han producido algunos ejemplos significativos de los que damos cuenta.

A partir de la identificación de las viñetas publicadas en el periodo de observación, hemos realizado una primera selección por su relación con la pandemia por la COVID-19. Posteriormente, hemos asignado los diferentes trabajos a alguna de las siguientes categorías: a) Origen y transmisión del virus, b) Información, c) Alusión al miedo generado por la pandemia, d) Recursos sanitarios y sistemas de salud, e) Economía, f) Estado general del mundo, y g) Confinamiento. Estas categorías pueden sintetizar el pensamiento de El Roto sobre aspectos conceptuales, operativos, incidentales e instrumentales que han rodeado a la COVID-19. Con ello hemos confeccionado tablas (una para cada categoría) en las que incluimos los textos literales contenidos en las viñetas, así como

i. Los autores han solicitado permiso de reproducción a los autores de las viñetas, obteniendo el permiso de José María Pérez (Peridis), Flavia Álvarez-Pedrosa Pruvost (Favita Banana) y José Ruvio Malagón (Malagón); de Andrés Rábado (El Roto) no se ha obtenido respuesta. 


\section{LA PANDEMIA POR CORONAVIRUS A TRAVÉS DE VIÑETAS DE HUMOR GRÁFICO AGUSTÍN HIDALGO; BEGOÑA CANTABRANA; COVADONGA DIEGO; IÑIGO HIDALGO}

una interpretación tentativa de los mismos a partir de los que se describen los resultados.

Para la elaboración de los resultados hemos elegido una descripción narrativa utilizando como base los contenidos de las viñetas incluidos en las tablas antedichas.

\section{RESULTADOS Y COMENTARIOS}

De forma premonitoria, el día 27 de diciembre de 2019, El Roto incluía una plegaria en la viñeta del día que invocaba "Big Data que están en los cielos, santificados sean tus números". Y no sabía él, ni sabíamos nosotros, cuán importantes iban a ser los números y el big data en los próximos meses que, además, vendrían cargados de descalificaciones e insultos por la utilización interesada de los mismos. Esperanzado, inauguraba el año 2020 con el deseo de que los acontecimientos del año no rompieran el equilibrio que anunciaba la igualdad de peso en ambos platillos de la balanza. No obstante, el día de Reyes ya apunta la primera contrariedad cuando uno de los niños de la viñeta confiesa haber pedido a sus Majestades "otro país" pero que no se lo han traído.

La primera alusión al virus (un ovillo con espículas) es para reclamar "Cuando estéis todos vacunados, avisadme para mutar". Es el día 10 de enero y han pasado 10 días desde la comunicación de China a la OMS de una epidemia de neumonía no filiada que devino en la COVID-19. A partir de este momento, hemos analizado las viñetas de los humoristas del diario El País en la edición impresa hasta el día 30 de junio. Tal vez no esté de más recordar que el primer caso de coronavirus confirmado en España se detectó el día 2 de febrero en la isla de La Gomera siendo un turista alemán el afectado. Los comentarios que siguen se han elaborado a partir de 166 viñetas.

La base del relato son las viñetas de Andrés Rábago (El Roto). En consecuencia, a menos que se especifique otra atribución de autoría, se basa en sentencias de este autor.

\section{Origen y transmisión}

Coincidiendo con la declaración por la OMS de estado de emergencia mundial, un globo terráqueo con máscara de alta seguridad nos anuncia que entramos en "PANDEMIA". El impacto de la pandemia ha sido tan amplio que ha afectado a prácticamente todos los sectores y actividades cotidianas. No es infrecuente que intelectuales de diferente origen y tendencias anuncien nuevos males, la pérdida del mundo que estábamos viviendo y la producción de revoluciones sociales que cambiarán la forma de vida actual, según sugiere la viñeta 1 . Al mismo tiempo, se avanza que las transformaciones que impondrá la pandemia serán tales que parece que se esté hablando de alguna peste bíblica. No obstante, el racionalismo que ha ido relegando a la mitología, nos ofrece un consuelo cuando un prelado con tiara y báculo anuncia "Tengo buenas noticias: no es un castigo divino, es una cuestión médica", sobre la

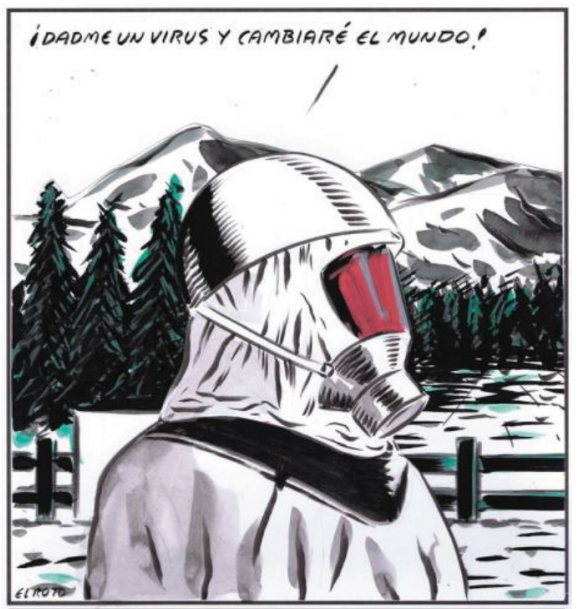

Viñeta 1. El Roto. El País, 7 de julio de 2020. 
LA PANDEMIA POR CORONAVIRUS A TRAVÉS DE VIÑETAS DE HUMOR GRÁFICO AGUSTÍN HIDALGO; BEGOÑA CANTABRANA; COVADONGA DIEGO; IÑIGO HIDALGO

que "Sabemos todo sobre el virus menos el origen y el fin".

Respecto al origen, alude a las condiciones de tensión a las que hemos sometido al medio ambiente como sugiere una viñeta en la que la tierra, en medio del marasmo, exclama "iNo puedo respirar!". También implica a las condiciones de cría intensiva de animales para consumo humano. Esta circunstancia, que El Roto ejemplifica en un grupo de cerdos en una pocilga, es propicia para el intercambio de agentes infecciosos y para que, por pura competencia evolutiva, se produzcan mutaciones de viejos conocidos o surjan nuevas cepas por mezclas aleatorias de genomas $^{14}$. Las posibilidades son tantas que uno de los cerdos sugiere al que anuncia que está desarrollando un nuevo germen, "no lo sueltes aún" porque "hay overbooking". También sugiere en este ámbito que las zoonosis siguen siendo la principal causa de enfermedades infecciosas humanas ${ }^{15}$ por mucho que "De la biblia lo único aún vigente son las langostas", si hacemos caso a un personaje ante la risa sardónica de un coronavirus semioculto.

De la rápida transmisión culpa a la movilidad, como han dicho todos los popes de la comunicación, de la salud pública y de la infectología, hasta el punto de proclamar que "Viajar permite conocer nuevos virus" y que "Huyendo del fuego, lo propagaban". La responsabilidad individual es aludida en una historia en la que dos personas con mascarilla se besan bajo la leyenda " $i P R E$ CAUCIÓN! iEL AMOR ES CONTAGIOSO! También Malagón insiste en el mismo papel del viaje (desplazamiento), mediante el recurso a una pelota de golf camuflada de coronavirus que es impulsada a distancia. Además, se nos ha ofrecido una idea de la extinción de la pandemia que, en el ideario de Andrés Rábago, ocurrirá "cuando los contagiados sean innumerables", en alusión a la inmunidad de rebaño. Mientras tanto, "Un turismo sin turistas" es "una solución alternativa".

\section{Información}

Un aspecto importante de la pandemia ha sido la comunicación, su calidad y, por ende, la información que le ha llegado al ciudadano a través de los medios que tienen el potencial de controlar lo que se difunde y de educar y controlar a las estructuras de poder ${ }^{16}$. Por eso, una de las viñetas de El Roto recuerda que "Quien controla los medios, controla los miedos", o que "La información es cara porque requiere mucha manipulación", ante lo que puede surgir información alternativa como nos recuerda el 3 de marzo con la siguiente sentencia "Unos días nos alarman y otros nos tranquilizan".

Algo preocupante en la fase inicial de la pandemia han sido las noticias falsas, algo más peligroso que la propia COVID-19 17 por la incertidumbre y desconfianzas que generan. Por eso Rábago, como forma de denunciar el problema, insiste en que "Si ha estado en contacto con un bulo, lávese las manos", califica como rumores el "Se decía que algunos laboratorios de investigación hibernaban murciélagos", y denuncia la reiteración machacona en los mismos aspectos del tema (el monotema durante tres meses), hasta el punto de que "De tanto hablar de lo mismo perdieron el habla". Toda esta información es peligrosa porque genera miedo y "Ese síque es contagioso". La parcialidad informativa también está presente en la siguiente queja "De las vacunas figuran las patentes, de los virus no". El deterioro de la veracidad es tal que la misma verdad se considera un escándalo, o eso sugiere la viñeta en la que cuando un hombre confiesa a la mujer "Lo siento, he descubierto que amo a la verdad", ella pregunta "¿Y quién es esa zorra? (viñeta 2). La advertencia sobre la manipulación, sobre la que ha insistido reiteradamente, se produce de forma precoz (el 29 de enero) mediante un dibujo en el que un hombre mira a un "enmascarado" al que 


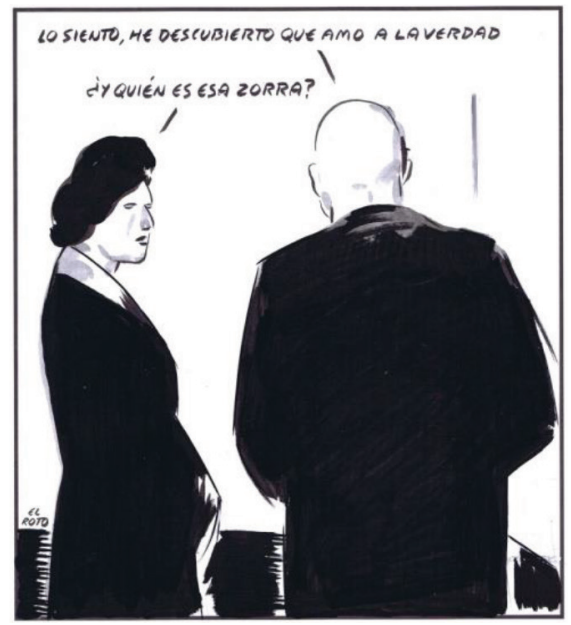

Viñeta 2. El Roto. El País, 5 de septiembre de 2020.

pregunta "¿Contra el coronavirus?" No, contra la manipulación" es la respuesta.

En un momento determinado, en los primeros días de febrero, El Roto trae a colación la intervención política para el control de la información o, de forma más cruda, para imponerla de forma dictatorial. Alude, naturalmente, a China cuando escribe que "Las mascarillas tapan las mordazas", que "Todo está bajo control, permanezcan asustados", o que "La censura lo cura todo".

\section{Estado general del mundo}

Ernst Mayr ${ }^{18,19}$, médico dedicado a la biología evolucionista que vivió más de 100 años, nos dejó dos libros imprescindibles. Uno lleva por título "Así es la biología" y el otro "Por qué es única la bilogía". De su lectura, uno saca enseñanzas que permiten entender que, como anuncia el título de uno de los libros, la biología es única y que se diferencia ( $y$, por tanto, los seres vivos nos diferenciamos) de los sistemas físicos, inertes, en un buen puñado de aspectos, entre ellos que somos programas evolucionados a lo largo de 3.800 millones de años, que tenemos capacidad para sintetizar y descomponer en moléculas inorgánicas, poseemos mecanismos reguladores a todos los niveles, que estamos organizados en sistemas complejos y ordenados, por lo que deben ser regulados, que somos sistemas teleonómicos (preparados para realizar actividades dirigidas a un objeto), que las unidades básicas de nuestra organización (células, organelas, moléculas...) son muy pequeñas pero de gran flexibilidad de desarrollo y evolución o que tenemos un ciclo vital y que somos sistemas abiertos; es decir, estamos en continuo contacto y permanente intercambio con el medio que nos rodea, del que tomamos los alimentos que nos nutren, el agua que nos hidrata, el oxígeno que nos permite respirar, la luz y el calor necesarios para nuestro metabolismo, etc. Entender y aprender esto es algo tan elemental y tan crítico para nuestra subsistencia que resulta inconcebible el desprecio al medio ambiente, la ceguera con la que nos relacionamos con él, y la inconsciencia con la que intervenimos en la naturaleza cercenando nuestro futuro.

El Roto ha mostrado a lo largo de su trayectoria una gran sensibilidad tanto por el respeto a la naturaleza como por la estupidez humana. $Y$ una buena muestra de ello son las viñetas dedicadas a responsabilizar al maltrato a la naturaleza, al cambio climático y sus consecuencias, a la manipulación ambiental, de la crisis mundial por la actual pandemia. Así, representa en su viñeta "El mundo está BAJO PRESIÓN" al globo terráqueo comprimido por dos férreas manos, situación ante la que la tierra ha adoptado medidas defensivas: "El hombre se comporta como un cuerpo extraño, tuve que activar mis defensas".

Los motivos que han provocado la situación actual se centran, a juicio del humorista en dos grandes componentes. En el primero se agrupa la actuación irresponsable del hombre, erigido en el ser supremo de la naturaleza y con licencia para hacer y deshacer sobre ella. Por eso, es a los hombres a quienes dice, por boca de un pez que agoniza en un litoral: icंQuién os hizo creer 


\section{LA PANDEMIA POR CORONAVIRUS A TRAVÉS DE VIÑETAS DE HUMOR GRÁFICO AGUSTÍN HIDALGO; BEGOÑA CANTABRANA; COVADONGA DIEGO; IÑIGO HIDALGO}

que la tierra es vuestra?! El otro grupo de causas tiene que ver con el cultivo de la ignorancia, con el no querer darse cuenta de la situación. En este sentido, son ilustrativas las viñetas en las que, por ejemplo, muestra un barco en la cresta de una ola turbulenta bajo el rótulo "Nosotros vamos bien. Es el mar el que va a la deriva", o la que representa a un hombre tapándose los ojos con una mascarilla a la que titula como "Propuesta para un correcto y eficaz uso de las mascarillas en la fase cinco", que alcanza la situación extrema de disponer la mascarilla cubriendo todo el rostro, a lo que denomina "Uso correcto de la mascarilla. Fase final", culminando de esta forma la representación del no querer saber nada de qué va la historia de la relación entre hombre y naturaleza.

Pero esto no debe extrañarnos porque habitamos un mundo caracterizado por una "Sociedad hiperconectada; ciudadanos programados" e insensible, y no comprometida con su destino, se constata que "El mármol de las instituciones resultó ser de escayola", lo que permite traer a colación la obra de sociólogos y literatos, tales como Zygmun Bauman y su Vida líquida ${ }^{20}$ ("sociedad en la que las condiciones de actuación de sus miembros cambian antes de que las formas de actuar se consoliden en unos hábitos y en una rutina determinadas"), Todorov con LoS enemigos íntimos de la democracia ${ }^{21}$, o el propio Antonio Muñoz Molina en su ensayo Todo lo que era firme ${ }^{22}$ que dan cuenta de cómo los valores han sido sustituidos por valores económicos, ... hasta el punto de que "El ser humano se dejó de fabricar por su excesivo coste".

Denuncia El Roto algunas características de la sociedad líquida cuando indica que "Cuando llegó la pandemia los agentes privatizadores se ocultaron", protesta por los objetivos equivocados cuando dice "A ver cuándo sacan una vacuna contra las guerras, que esas sí que matan", reincide con "De una vacuna contra el hambre y las guerras, de eso no se ocupan", y alerta sobre la falta de utopías y de líderes políticos "Sobran estadísticas y faltan estadistas", lo que supone una llamada de atención no sólo sobre el crepúsculo mundial de estadistas sino también una advertencia sobre el "dataismo", penúltima secta de nuevos redentores que nos van a salvar mediante la explotación y uso de los datos ${ }^{23,24}$.

En esta situación de caos, en un mundo que echa humo, "Entonces llegó el virus y mandó parar", poniendo en evidencia que "Se equivocaron de paciente, la que está realmente mal es la tierra". A partir de este estado, en la nueva normalidad, "New Age", dice El Roto, AC y DC pasarán a ser acrónimos de "Antes del confinamiento" y "Después del confinamiento". Sin embargo, es posible que esta sociedad ensimismada no entienda más allá de lo que reflexiona una pareja en la viñeta del 5 de mayo "Tendremos que ir pensando donde no viajar este verano".

\section{Sobre el confinamiento}

Flavita Banana presenta el 31 de marzo, en la fase más dura del confinamiento, un diálogo entre toros en una dehesa, en el que uno comenta, como el que no quiere la cosa "iHe oído en algún lado que ahora los encierros son de humanos!".

Mucho se ha debatido acerca del confinamiento, no porque se discuta su papel en el control de las epidemias (algo acreditado desde la antigüedad, razón por la que todos los gobiernos han recurrido al mismo ante la extensión y la gravedad de la pandemia), sino porque han visto la oportunidad de convertirlo en arma arrojadiza contra el adversario político. Si bien en el primer momento, ningún partido político se atrevió a oponerse, a partir de la primera prórroga, las disputas fueron en aumento sin otro objetivo aparente que la obtención del rédito político, de acoso y derribo al gobierno y/o de obtención de prebendas financieras o territoriales, que han explorado los humoristas con un respaldo al confinamiento como medida de salud pública. En este sentido, Flavita Banana realiza una viñeta 


\section{LA PANDEMIA POR CORONAVIRUS A TRAVÉS DE VIÑETAS DE HUMOR GRÁFICO AGUSTÍN HIDALGO; BEGOÑA CANTABRANA; COVADONGA DIEGO; IÑIGO HIDALGO}

en la que un escalador llega a la cumbre de una montaña en la que encuentra un cartel que indica "Gracias por quedarte en casa". El Roto, por su parte, tira de sarcasmo para resaltar que "La era aeroespacial terminó en confinamiento". Lo que es indudable es que la pandemia y el coronavirus han ocupado nuestros pensamientos durante meses. iNo me lo puedo quitar de la cabeza!" es la leyenda que acompaña a dos personas con "cabeza de coronavirus".

Sin embargo, el confinamiento, más allá de un hecho, es un fenómeno que permite diferentes aproximaciones analíticas. Es, también, una circunstancia que ha obligado a cambios conductuales, ha condicionado alteraciones emocionales, y ha provocado modificaciones en el ámbito laboral con la consagración del teletrabajo o "Trabajo en remoto, sin horario"; Es decir, una auto-explotación. Y, por supuesto, una invitación a las conjeturas sobre si el confinamiento es una medida sanitaria o una prueba de docilidad. Así lo plantea la conversación entre dos personajes de El Roto en una viñeta del 29 de mayo. Dice uno "Le hemos hecho la prueba a toda la población. ¿De la COVID? -pregunta el otro-; No, de obediencia", es la respuesta. El problema planteado permanecerá durante tiempo en las páginas escritas por filósofos, sociólogos, políticos, etc. a pesar de que desde el mundo de la ética y de la justicia se han producido pronunciamientos que inequívocamente anteponen los derechos de salud comunitaria a las libertades individuales de movimiento y/o reunión ${ }^{25,26}$.

Una pregunta que puede plantearse es si es posible vivir en confinamiento o, como se dice ahora (para la vuelta al colegio de los más pequeños o para las competiciones deportivas), si se puede vivir en una burbuja. El Roto, lo tiene claro "Es posible vivir en una burbuja, pero sólo si eres aire". Pero también, para algunas personas "Quedarse en casa resultaba una experiencia exótica. ¡Qué lugar!, exclama un señor acomodado ante su casa, iEs nuestro hogar, cariño!, le responde su pareja.

El confinamiento, para no pocas personas ha sido un aburrimiento difícil de gestionar, por lo que Flavita Banana (viñeta 3) dibuja una viñeta en la que un personaje pregunta "Qué tal llevas el aburrimiento" y otro contesta "Hoy el aburrimiento me lleva a mi". Para otros, puede haber sido una experiencia religiosa (o casi) que El Roto pasa por el cedazo de la sátira "Durante el confinamiento escuché extasiado la voz de Dios, pero cuando acabó, volvió la publicidad". De hecho, la práctica religiosa se ha resentido, con el agravante de que ha coincidido con la Semana Santa y ha provocado la frustración de muchos fieles por no poder asistir a los oficios, ni acompañar a los pasos de las procesiones, ni celebrar misa en las iglesias, lo que ha molestado especialmente a los dirigentes eclesiásticos, algunos de los cuales han incurrido en desafíos a la autoridad civil. La clausura de las actividades religiosas de Semana Santa ha tenido reflejo en algunas viñetas editoriales de El País. En la del 9 de abril, El Roto dibuja una cruz clausurada mediante tablas cruzadas en la que luce el rótulo "Cerrado por

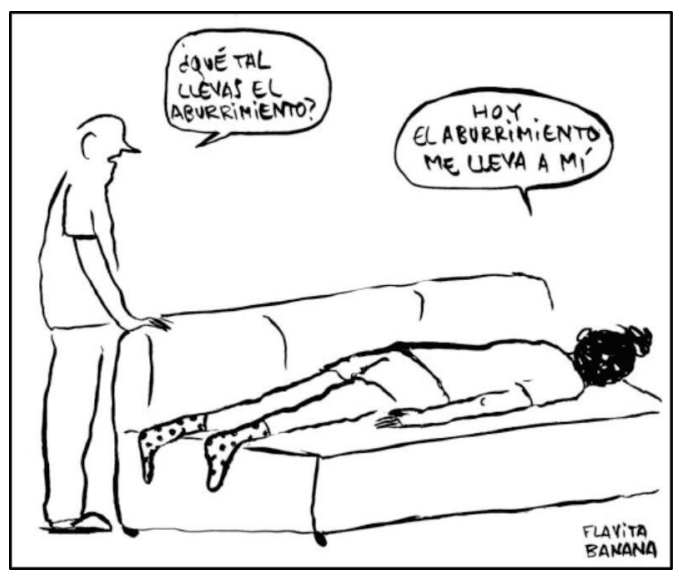

Viñeta 3. Flavita Banana. El País, 2 de abril de 2020. 


\section{LA PANDEMIA POR CORONAVIRUS A TRAVÉS DE VIÑETAS DE HUMOR GRÁFICO AGUSTÍN HIDALGO; BEGOÑA CANTABRANA; COVADONGA DIEGO; IÑIGO HIDALGO}

Coronavirus"; en otra del mismo autor, un Cristo crucificado pregunta al único feligrés que lo contempla ¿Dónde están los fieles y los turistas? A lo que le responde "En casa, rezando". En la última, un personaje con escafandra y característico halo divino llama a capítulo a los creyentes: " $i \mathrm{Hom}$ bres de poca fe en la ciencia, ¿'por qué dudáis?!".

La restricción de movilidad ha tenido repercusión en los hábitos alimentarios, no solo en la comida repetitiva y desequilibrada que la Comunidad de Madrid contrató para los niños que Malagón (viñeta 4) representa con dos niños huyendo de un fragmento de pizza bajo el rótulo "Menú escolar en tiempo de pandemia", sino que ha dado lugar a un exceso de alimentación en muchas familias, lo que se ha representado en una viñeta que muestra a través de una ventana a dos personas opulentas y glotonas que parecen festejar "De esta salimos rodando", mientras fuera, contra la fachada de la misma casa, otra persona pide limosna. A esta Imagen los sociólogos y los epidemiólogos han puesto voz, resaltando que la pandemia y las medidas adoptadas por algunos gobiernos de Comunidades Autónomas han aumentado las desigualdades sociales ${ }^{27,28}$.

Puestos a buscar contradicciones, a los presidiarios se les pone en libertad para prevenir el contagio en las prisiones; a los ancianos se les aísla en su confinamiento e incluso se les prohíbe, en alguna Comunidad Autónoma, su traslado a

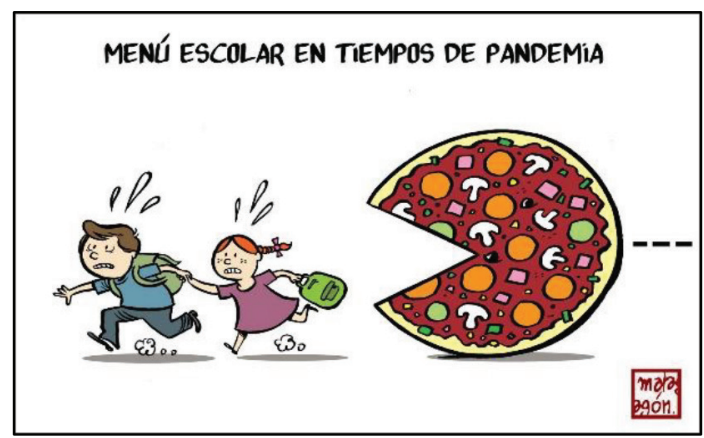

Viñeta 4. Malagón. El País, 10 de mayo de 2020. instituciones sanitarias. Confinar a los confinados es visto por Flavita Banana (viñeta 5) como una implementación de su tradicional aislamiento, privándoles de las visitas y condenándolos a una mayor deprivación afectiva como refleja la viñeta de más abajo:

El confinamiento ha aumentado las horas de convivencia familiar lo que ha provocado tanto un aumento de la natalidad como de los divorcios. Este abarrotamiento de las viviendas ha contrastado con el espacio público vacío, con las salidas programadas, ajustadas a horarios y a necesidades elementales. En este contexto, "Los apartamentos vacíos, semejaban nichos". Pero lo que ha ocupado un lugar relevante durante el confinamiento ha sido el miedo, tanto institucional como personal, al SARS-CoV-2 y a las consecuencias de su contagio. Por eso, El Roto le ha dedicado varias viñetas. En una significa la ambigüedad o la indecisión de los ciudadanos cuando, bajo el rótulo de "PATOLOGÍA" una persona con mascarilla proclama "Tengo miedo a salir y también a quedarme encerrada",

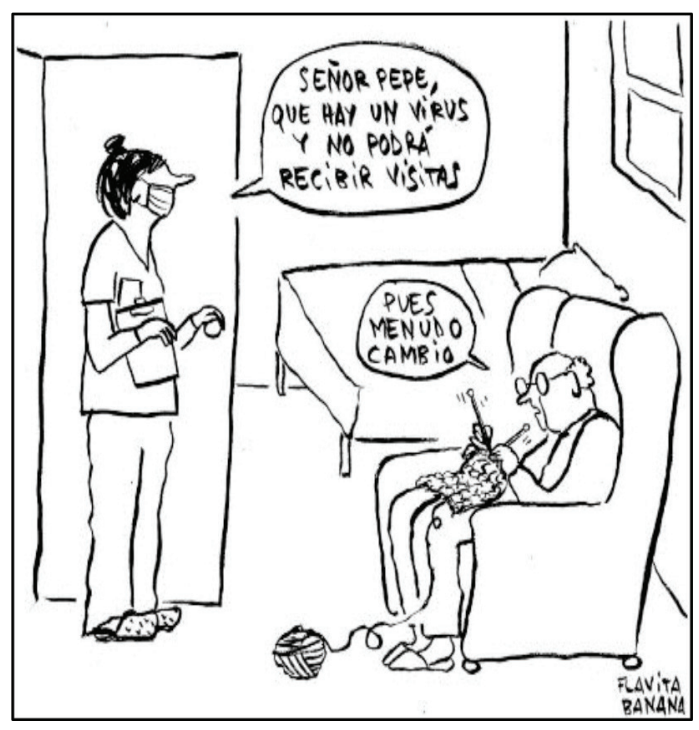

Viñeta 5. Flavita Banana. El País, 3 de abril de 2020. 


\section{LA PANDEMIA POR CORONAVIRUS A TRAVÉS DE VIÑETAS DE HUMOR GRÁFICO AGUSTÍN HIDALGO; BEGOÑA CANTABRANA; COVADONGA DIEGO; IÑIGO HIDALGO}

o ejemplifica el miedo a salir de casa mediante un personaje subido a un coronavirus bajo el rótulo "Crónicas del coronavirus", o bajo el mismo rótulo, una persona con la cara semicubierta por una prenda de abrigo, parece reflexionar "Yo no salgo de mí mismo para evitar contagios". Claro que, en el estricto cumplimiento de lo que eleva a la categoría de "Normas", "Se podrá salir a pasear siempre que se haga encerrado en sí mismo".

\section{Miedo}

Como indicó Juan Roig, propietario de una cadena de supermercados, en algún momento a lo largo de la pandemia, "Si algo agrava la situación es el miedo". En este mismo sentido se manifiesta El Roto en la viñeta 6. Este mismo autor nos ha dejado otras viñetas relacionadas con el miedo. Así, "El miedo es un microscopio que todo lo agranda", que consigue que "Todo lo que se movía les parecía sospechoso", que, como indica un personaje asustado en medio del marasmo, "Sé que esto es una pesadilla pero no me atrevo a despertar por si la realidad es peor", que es algo que se vuelve circular como sugiere un personaje que camina sobre un coronavirus bajo el rótulo

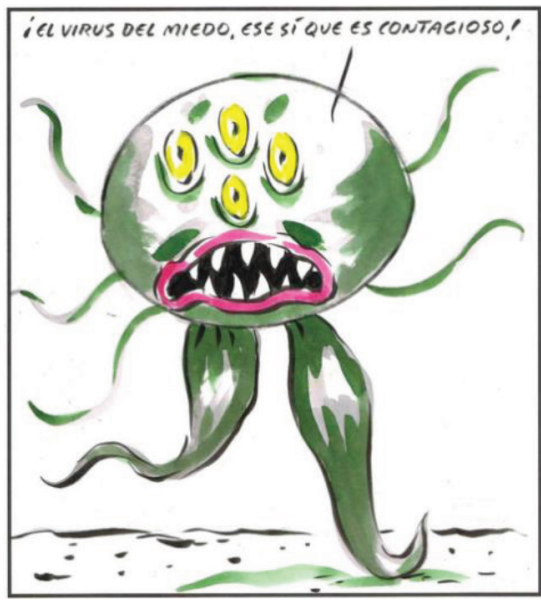

Viñeta 6. El Roto. El País, 28 de enero de 2020.
"CRONICAS DEL CORONAVIRUS (MIEDO A SALIR DE CASA)".

No es despreciable el miedo al contagio porque el virus se contagia por todas las vías, como sugiere la viñeta en la que, bajo el rótulo de "MIEDO MEDIÁTICO", representa al virus entrando por los oídos de los oyentes, lo que sugiere la importancia del boca a boca (irreflexivo) en la propagación de los fenómenos virales a lo que alude con una viñeta en la que dos hombres sin rostro y máscara corren mientras gritan; el uno, "iCorre, que viene! El otro ¿Quién? ¡El Miedo!, es la respuesta (viñeta 7).

Así mismo, pontifica con razón que "Los peligros que no existen son los que más miedos dan"; e ironiza con la imagen de un lineal de nichos acompañados por la leyenda "Tranquilos, aquí no hay peligro".

\section{Recursos sanitarios y sistemas de salud}

La pandemia actual ha puesto patas arriba al sistema de salud español, reputado como uno de los más solventes. La ensoñación de que el sistema era capaz de soportar lo que le viniera encima ha revelado eso, una ensoñación. Posiblemente nuestro sistema era de los más eficientes puesto que obtenía niveles de resultados muy buenos en comparación con la

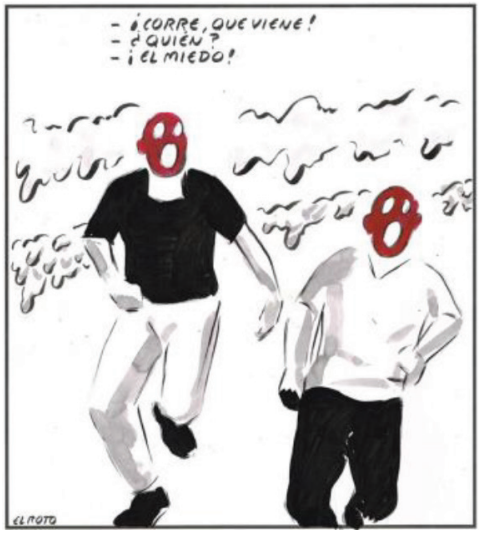

Viñeta 7. El Roto. El País, 15 de febrero de 2020. 


\section{LA PANDEMIA POR CORONAVIRUS A TRAVÉS DE VIÑETAS DE HUMOR GRÁFICO AGUSTÍN HIDALGO; BEGOÑA CANTABRANA; COVADONGA DIEGO; IÑIGO HIDALGO}

inversión pública. Pero ha necesitado del confinamiento de la población para el control de los contagios y que no colapsara la asistencia hospitalaria. Algunos aspectos del funcionamiento del sistema han sido abordados por los humoristas. Por empezar por algún sitio, podemos citar la historieta de Flavita Banana que resalta hasta qué punto el plástico ha llegado a ser imprescindible y objeto de demanda extrema durante la fase más crítica de la pandemia; para ello muestra a una persona con mascarilla poniéndose los guantes que reflexiona " $i Y$ pensar que hace unos meses nos manifestábamos contra el plástico!".

Ante la escasez de recursos sanitarios de prevención y evitación de contagios, en la fase más aguda se ha recurrido a prácticas y productos tradicionales de higiene. Un ejemplo es el "monumento" erigido a la lejía por El Roto con su dibujo de un bote de lejía de uso alimentario encima de un pedestal, un remedio barato y eficaz desinfectante; precisamente por sus recomendaciones del uso de la hidroxicloroquina (medicamento cuya eficacia ha sido desacreditada mediante ensayos clínicos) y la lejía, el presidente de EEUU Donald Trump ha abochornado al mundo (viñeta 8).

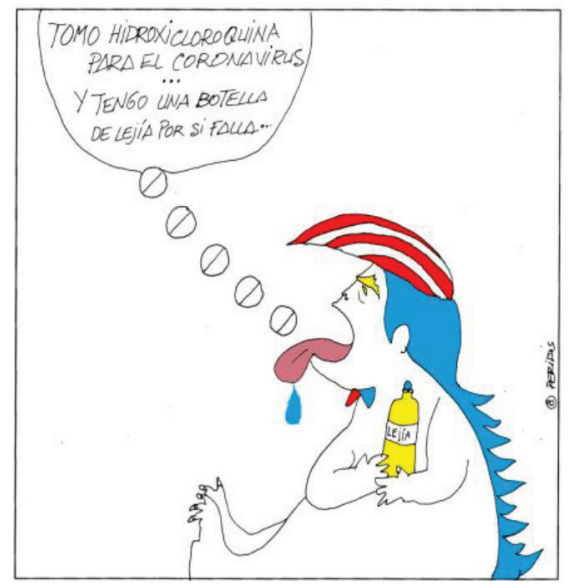

Viñeta 8. Peridis. El País, 20 de mayo de 2020.
Y es que se han utilizado las "armas" disponibles como sugiere la viñeta presidida por la leyenda "CRONICAS DEL CORONAVIRUS", en la que un personaje dispara contra los virus invocando "No se acerquen". Sin embargo, no ha olvidado sugerirnos que la literatura puede ser un eficaz acompañamiento durante la enfermedad $^{29,30}$, a la que aporta un componente terapéutico. Su recomendación: "Un poderoso desinfectante. La poesía".

En buena parte de las CCAA, los Centros de Salud fueron cerrados para derivar a sus profesionales a hospitales y otras instalaciones (p. e. IFEMA) acondicionados como centros asistenciales para atender a enfermos agudos. En cambio, el cuidado de los crónicos se mantenía con precariedad y, generalmente, era necesario solicitar cita previa. Por eso, una viñeta recuerda esta situación con la leyenda "Ya no te dejan morir sin cita previa".

En el trabajo de los humoristas, no se ha dedicado mucha atención a la labor de los sanitarios, tal vez porque se considera demasiado seria como para ponerla en solfa. Sí ha tenido el reconocimiento social del aplauso diario y la concesión del Premio Princesa de Asturias de la Concordia 2020, pero poca presencia en el humor del diario El País. Posiblemente la única alusión es la que representa a un esforzado virólogo combatiendo a puñetazos al coronavirus. "Un virólogo en el gimnasio" es la leyenda que acompaña la ilustración. No puede descartarse que este comentario aluda a la falta de medios, como posiblemente es el caso en otra historia que representa una bolsa de tela con la imagen del coronavirus y la leyenda "Detente virus".

Junto a estos déficits, ha llamado la atención el desorden organizativo y la toma de decisiones ("Mandan esto y aquello para parecer autoridades"), que ha tenido uno de sus puntos más negros en las medidas adoptadas con las residencias de ancianos que ha conducido a una elevada mortalidad dado que, como se queja una anciana 


\section{LA PANDEMIA POR CORONAVIRUS A TRAVÉS DE VIÑETAS DE HUMOR GRÁFICO AGUSTÍN HIDALGO; BEGOÑA CANTABRANA; COVADONGA DIEGO; IÑIGO HIDALGO}

con limitaciones de movilidad "Las llamaban residencias, pero eran una morgue".

Otro desaguisado del período pandémico tiene que ver con las estadísticas. Es lamentable que, por aquello de la descentralización, España no disponga de un sistema ágil y robusto de registro de problemas de salud pública, cosa que sí tiene en otros ámbitos. En el curso de la pandemia, el baile de cifras ha sido constante, básicamente porque cada CCAA ha notificado cuánto, cuándo, cómo y lo que le ha parecido sin utilizar patrones comunes, más preocupados de la imagen propia que del problema común. Este problema ha afectado incluso a las estadísticas de mortalidad (o sobre-mortalidad), a las que se han incorporado valores de forma anárquica y centradas, con preferencia, en el coronavirus, lo que lleva a un personaje de El Roto a proclamar " ¿A los muertos de otras muertes no nos cuentan? ¿Por qué nos discrimináis?" (viñeta 9). Así mismo, un germen con cara de mal bicho protesta "iTodos los muertos se le atribuyen al dichoso coronavirus! ¿Es que los demás no matamos?", lo que alude a la ocultación de las otras muertes.

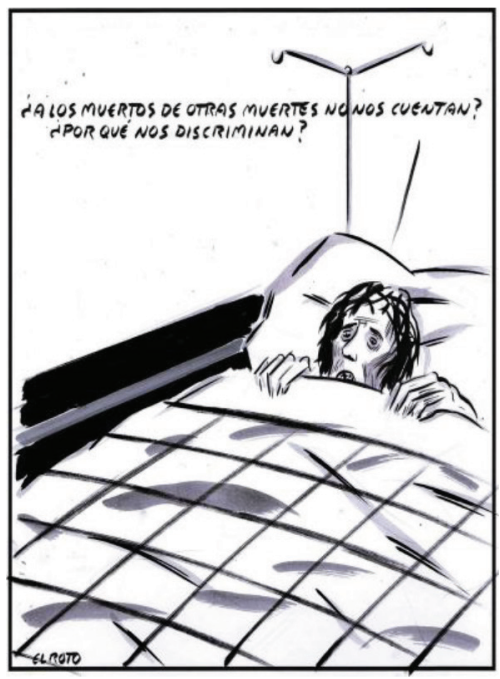

Viñeta 9. El Roto. El País, 25 de mayo de 2020.
Los esfuerzos de investigación no han tenido mucha representación en las viñetas, únicamente en la que un científico recoge excrementos de un "espécimen experimental" con cabeza de coronavirus, bajo el rótulo "La Vacuna". La viñeta es compleja porque puede aludir tanto a que la investigación sobre la vacuna es una mierda, como que obligan a investigar con recursos de mierda. En ambos casos, la pertinencia es discutible, aunque la oportunidad es de rabiosa actualidad.

En todo caso, el mayor "Descubrimiento Científico" puede haber sido la constatación de que "Cada ser humano tiene dos respiradores, pero los maltrata", lo que supone una llamada a la responsabilidad ciudadana y social, convencido el humorista de que cuando se produzca una conjunción astral entre los científicos y, al unísono, hablen con voz profética, no aportarán algo distinto a lo que describe la viñeta de El Roto del 25 de abril: habló el profeta y dijo " $i H e$ encontrado la vacuna! ¿Cuál es, le preguntaron? - Otra forma de vivir", les contestó, "pero le tomaron por loco"

El trabalenguas del desconfinamiento también ha estado presente. Peridis se hace eco del mismo en unos días en los que era difícil saber dónde estábamos dada la abundancia de comunicados contradictorios (o casi) y las sucesivas aclaraciones a los mismos. La imagen de desconcierto del Dr. Simón y la leyenda que le asigna el humorista, son ilustrativos de la situación (viñeta 10).

Tal vez la reincidencia en la atención al medio y el énfasis en una vida de acuerdo con los recursos consiga que los gobernantes quiten el énfasis del mantra que sostiene que cuanto menos estado, mejor, porque habrá más opción de negocio privado. Esto nos ha llevado a un desmantelamiento progresivo de los servicios públicos que justifican la viñeta editorial del 9 de marzo, que muestra a una persona con gafas de seguridad y la cabeza ocupada por el coronavirus bajo la leyenda "Desmantelaron la sanidad 


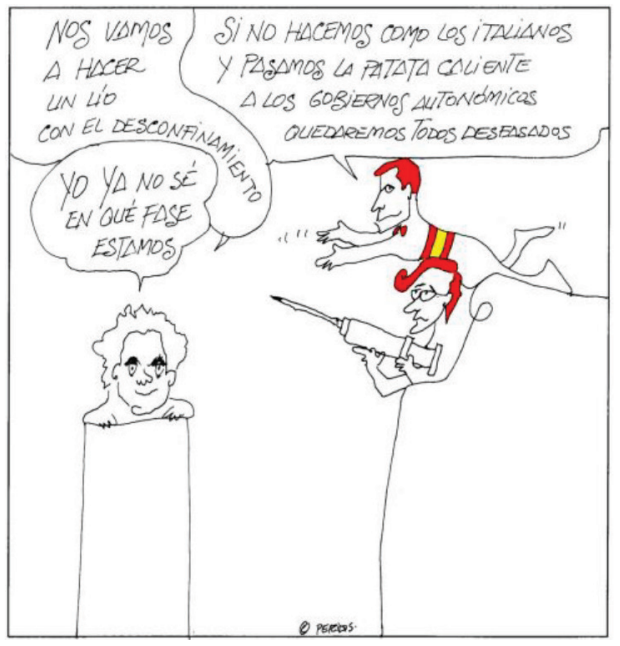

Viñeta 10. Peridis. El País, 17 de mayo de 2020.

pública. Cuando llegó el virus, la reclamaban". Y sin sanidad pública se producirá una involución de los cuidados y a la mayoría de la población no le irá bien, como sugiere la siguiente viñeta 11 de Flavita Banana.

No ha escapado a los humoristas el hecho de que la salud es un estado transitorio y que, como ya dijera Jules Romains en su obra Knock o el triunfo de la medicina ${ }^{31}$, escrita en el año 1923, "Caer enfermo", idea antigua que ya está superada ante los datos de la ciencia actual. La salud no es más que una palabra, que no habría ningún inconveniente en borrar de nuestro vocabulario. Por mi parte, sólo conozco gente más o menos aquejada de enfermedades más o menos numerosas, de evolución más o menos rápida. Naturalmente si usted les dice que gozan de buena salud, ellos no desearán otra cosa que creerles".

Esta precariedad de la salud y la necesidad de prevención, es algo que nos recomiendan las compañías de seguro de vida y asistencia sanitaria, los bancos y los planes de inversión y pensiones, la sanidad privada, la medicina mediatizada por la industria de recursos sanitarios y su voluntad de aumentar los beneficios ${ }^{32}$. El Roto, tira de cinismo para recordar (el día 6 de marzo) que "La salud es una enfermedad asintomática", tan asintomática, insiste, como nuestra democracia: "Tenemos una democracia asintomática, en las pruebas da positivo, pero no la notamos".

\section{La crisis política}

La crisis política que ha acompañado a la sanitaria ha sido dibujada por José María Pérez (Peridis) que ha subido a la columna de los personajes relevantes al ministro de sanidad Salvador Illa y al director del Centro de Coordinación de Alertas y Emergencias Sanitarias del Ministerio de Sanidad, Fernando Simón, la cara pública de

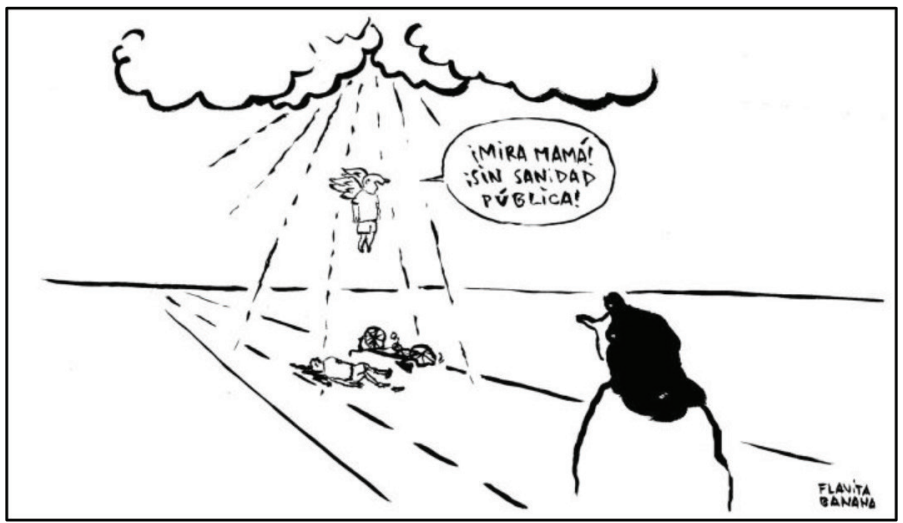

Viñeta 11. Flavita Banana. El País, 3 de julio de 2020. 


\section{LA PANDEMIA POR CORONAVIRUS A TRAVÉS DE VIÑETAS DE HUMOR GRÁFICO AGUSTÍN HIDALGO; BEGOÑA CANTABRANA; COVADONGA DIEGO; IÑIGO HIDALGO}

la comunicación oficial sobre la pandemia por la COVID-19. Peridis se ha hecho eco de los esfuerzos para contener la extensión de la enfermedad "Estamos aplanando la curva", la persecución del coronavirus por todos los rincones acompañado del ministro Illa al que advierte "iSalvador! iTen cuidado con el bicho que es muy traicionero! iNo vamos a bajar la guardia!", responde el ministro mientras que el coronavirus, escondido tras una roca, exclama "No me cogeréis vivo antes de que mute". Fernando Simón, a la postre, ha sido señalado como el culpable de todos los males "por dar la cara".

Pero, sobre todo, Peridis ha glosado el comportamiento de los políticos y la utilización de la situación para sacar réditos electorales, competenciales y económicos como muestra la siguiente viñeta del 10 de junio (viñeta 12) que ilustra las complejas negociaciones para prorrogar el estado de alarma hasta el fin del confinamiento.

\section{Economía}

La economía ha patrimonializado buena parte de la información sobre la pandemia y se ha convertido en un arma arrojadiza entre

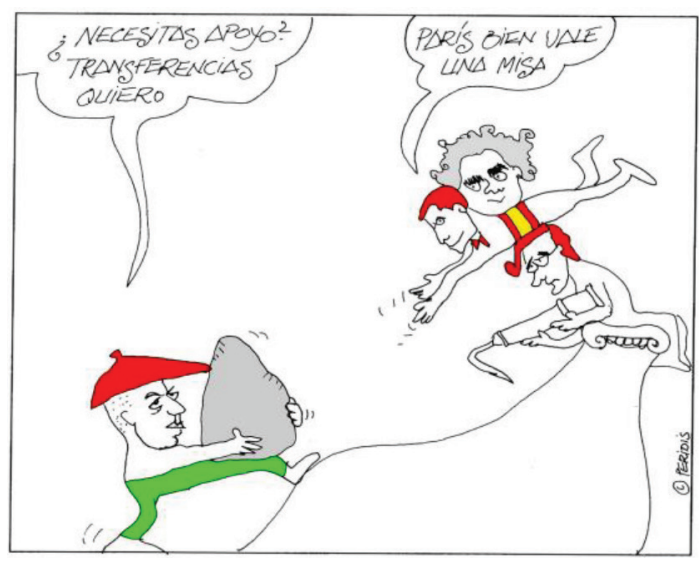

Viñeta 12. Peridis. El País, 10 de junio de 2020. facciones en litigio. Ninguna medida adoptada ha gozado de unanimidad más allá de la aprobación de la Renta Mínima Vital y de las medidas de protección tanto para la ciudadanía como para la empresa. En este contexto, el trabajo de los humoristas incide en aspectos que son habituales desde la crisis económica de 2008 y en la adopción de las draconianas medidas impuestas por el gobierno del Partido Popular de aquel entonces.

Si bien no se oculta la gravedad de la situación ("ila economía, esa sí que va a necesitar respiradores!"), el trabajo de El Roto se ha centrado en resaltar los aspectos sociales que suelen ser comunes a todas las crisis económicas, empezando por una observación precoz o premonitoria del 15 de enero ("El mercado lo ve todo") que alude a la sensación de sentirse observado y controlado por el dios de la economía. También, como en cada crisis económica, se avecina un enriquecimiento extra para los más poderosos para los que "La pobreza es una mina de oro" $y$, de hecho, ya de forma precoz representa en una viñeta la imagen de un tiburón con una aleta postiza de la paz, que implica el aviso de que los tiburones están al acecho, premonitorio de aquella otra en la que bajo el rótulo de " $L a$ bolsa o la vida" (una tradicional invocación de los atracadores), se representa a un ejecutivo que accede a un avión portando como equipaje un maletín (también tradicional alusión a la fuga de capitales), y una bolsa con forma de "coronavirus" que, significativamente, le acompaña.

Mientras tanto, los empresarios y gente poderosa en general "Hacían grandes gestos de solidaridad, pero no entregaban nada" al tiempo que "utilizaban la izquierda y la derecha para frotarse las manos" y seguían ordeñando los beneficios como sugiere la viñeta que muestra una ubre de vaca moteada de coronavirus bajo el rótulo "Negocios. Alguien la está ordeñando".

Para terminar, traemos a colación el antagonismo sempiterno entre los objetivos de clase. Para los poderosos "Conviene ampliar la distancia 


\section{LA PANDEMIA POR CORONAVIRUS A TRAVÉS DE VIÑETAS DE HUMOR GRÁFICO AGUSTÍN HIDALGO; BEGOÑA CANTABRANA; COVADONGA DIEGO; IÑIGO HIDALGO}

entre ricos y pobres para evitar contagios" que El Roto pone en boca de dos enmascarillados que brindan, y que Malagón en su historieta "Distancia Social" representa también a dos hombres, uno con mascarilla convencional mientras el otro usa por mascarillas billetes de 100 euros". Para la ciudadanía, en cambio, lo crítico es " $i Q u e$ se dejen de reconstruir la economía, queremos otra nueva!".

Pero lamentablemente, como reflexiona la escultura La Esfinge (ataviada con mascarilla para la ocasión) en su milenaria soledad, "Cuando todo esto pase nada volverá a ser igual... iMenos lo de siempre!". Claro que dentro de ese siempre tendremos el enorme poder protector del humor que, como sugiere el psiquiatra Rojas Marcos ${ }^{33}$, tiene la "Función primordial de aliviarnos la tensión emocional, el miedo y la inseguridad".

\section{REFERENCIAS}

1. Landero L. Lluvia Fina. Barcelona: Tusquets; 2019.

2. Carbelo Baquero B. El humor en la relación con el paciente. Barcelona: Masson; 2005.

3. Wandersee JH. Humor as a teaching strategy. Am. Biol Teacher. 1982; 44(4): 212-218.

4. Agencia Canaria de Calidad Asistencial - ACCA. Forges y la Medicina. [Internet]. 17 de marzo de 2018. [Consultado el 22 de septiembre de 2020].

5. Forges. Sinopsis de médicos 1. Madrid: Aguilar; 1997.

6. Forges. Forges inédito. Barcelona: Espasa Calpe; 2019.

7. Chumy Chumez. Cartas de un hipocondríaco a su médico de cabecera. Madrid: Edaf; 2000.

8. Gorman J. Primeros auxilios para hipocondríacos. Madrid: Temas de hoy; 1988.

9. Muñoz Rengel JJ. El asesino hipocondríaco. BarceIona: Plaza \& Janés; 2012.

10. Mayor Serrano MB. El cómic como recurso didáctico en los estudios de Medicina. Manual con ejercicios [Internet]. Barcelona: Cuadernos de la Fundación Dr. Antonio Esteve no 37; 2016.
11. Lalanda M. Con-Ciencia médica. Madrid: LID Editorial Empresarial; 2016.

12. Zárate F de, Calvi F. Una historia viral (de verdad). El País Semana I[Internet]. (2.286): 40-46. [Internet].

13. Mayor Serrano MB. Divulgación científica a través del lenguaje del cómic: la covid-19. Rev. Med Cine [Internet] 2020; 16(e): 71-81.

14. GPMB (Global Preparedness Monitoring Board). Un mundo en peligro. Informe anual sobre preparación mundial para las emergencias sanitarias. Junta de Vigilancia Mundial de la Preparación [Internet] septiembre 2019. [Consultado el 22 de agosto de 2020].

15. Rodríguez Ferri EF, Calvo Sáez A. Zoonosis. La cara oculta de la pandemia COVID-19. Rev Med Cine [Internet] 2020; 16(e): 249-261.

16. Murillo Rosado M. El incierto papel de los medios de comunicación en el nuevo contrato social del postcoronavirus. En Calvo JR, Kindelán C, Calvo Ma $\mathrm{A}$, editores. La gran pausa. Gramática de una pandemia. Barcelona: Malpaso; 2020, p. 137-148.

17. [IM]Farmacia. (Entrevista con Carlos Mateos) Nunca ha habido nada que genere tantos bulos como el coronavirus. [IM]Farmacia [Internet]. 24 de junio de 2020 [Consultado el 24 de junio de 2020].

18. Mayr E. Así es la biología. Madrid: Debate; 2005.

19. Mayr E. Por qué es única la biología: consideraciones sobre la autonomía de una disciplina científica. Madrid: Debate; 2006.

20. Bauman Z. Vida líquida. Barcelona: Paidós; 2010.

21. Todorov T. Los enemigos íntimos de la democracia. Barcelona: Galaxia Gutenberg, SL, 2012.

22. Muñoz Molina A. Todo lo que era sólido. Barcelona: Seix Barral; 2013.

23. Han B-Ch. La desaparición de los rituales. Madrid: Herder; 2020.

24. Rendueles C. Sociofobia. Madrid: Capitan Swing; 2013.

25. Quadra Salcedo T de la. Límite y restricción, no suspensión. El País [Internet]. 8 de abril de 2020. [Consultado el 8 de abril de 2020]. 


\section{LA PANDEMIA POR CORONAVIRUS A TRAVÉS DE VIÑETAS DE HUMOR GRÁFICO AGUSTÍN HIDALGO; BEGOÑA CANTABRANA; COVADONGA DIEGO; IÑIGO HIDALGO}

26. UNESCO. Declaración sobre el COVID-19: Consideraciones éticas desde una perspectiva global. Paris, 6 abril 2020 (traducción al español del Centro Nacional de Documentación en Bioética, La Rioja. España). [Internet]. 6 de abril de 2020 [Consultado el 8 de abril de 2020].

27. Franco M, Lazo M, Bilal U. Leganés, Iztapalapa y el Bronx: coronavirus y desigualdad en la ciudad global. El País [Internet]. 17 de mayo de 2020. [Consultado el 17 de mayo de 2020].

28. Franco M. La salud va por barrios en ciudades globales como Madrid. El país [Internet]. 13 de septiembre de 2020. [Consultado el 13 de septiembre de 2020].
29. González-Rodríguez S, Cantabrana B, Hidalgo A. El poder terapéutico de la narración. Rev Med Cine [Internet] 2016;12 (2): 110-21.

30. Hidalgo A, Cantabrana B. Efectos terapéuticos de la lectura. Rev Med Cine [Internet] 2017;13 (2): 75-88.

31. Romains J. Knock o el triunfo de la medicina. 3a Ed. Madrid: Bruño; 1991.

32. Blech J. Los inventores de enfermedades: cómo nos convierten en pacientes. Barcelona: Destino; 2005.

33. Rojas Marcos L. Prólogo. En Carbelo Baquero B. El humor en la relación con el paciente. Barcelona: Masson; 2015.p. 11-12. 


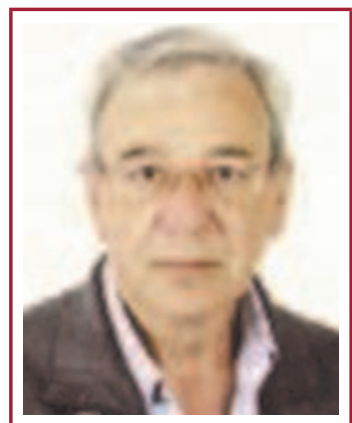

Agustín Hidalgo Balsera es licenciado y doctor en medicina por la Universidad Complutense de Madrid y Profesor de Farmacología de la Universidad de Oviedo. Entre sus áreas de interés se encuentra la repercusión social de los medicamentos y la representación social de la medicina y la enfermedad a través de las manifestaciones artísticas y los medios de divulgación científica y comunicación social.

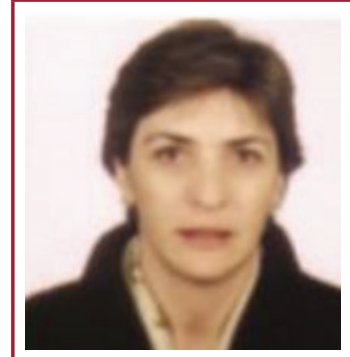

Begoña Cantabrana Plaza es Licenciada y Doctora en Medicina por la Universidad de Oviedo y Profesora Titular de Farmacología en la misma universidad. Su actividad científica se centra en la farmacología hormonal y dedica atención preferente a diferentes aspectos de la innovación docente en los Grados de Medicina y Enfermería.

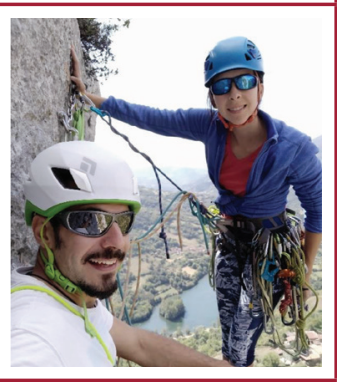

Covadonga Diego Alonso. Gaduada en Ingenieria Forestal y del Medio Natural, Master en Sistemas de Información Geográfica y Teledetección. Hasta la fecha trabaja como Ingeniera Forestal para Tragsatec en el desarrollo de cartografía temática e inventario para alimentar el servidor web del Principado de Asturias. Desde pequeña, la pasión por los animales y la naturaleza, han ocupado la mayor parte de mi tiempo libre hasta la fecha.

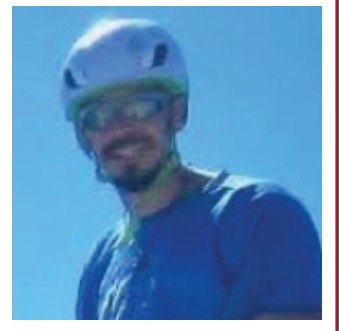

Iñigo Hidalgo Cantabrana. Graduado en Ingeniería Forestal y del Medio Natural, Master en Sistemas de Información Geográfica y Teledetección. Actualmente trabaja en I + D en el desarrollo y manejo de sensores embarcados en UAVs y automatización de procesos de generación de cartografía básica y temática para Babcock Mission Critical Service España. Apasionado de las montañas remotas y verticales, así como de la naturaleza en general y de los que, por naturaleza, son los míos. 